ARTICLE

https://doi.org/10.1038/s41467-019-10547-9

\title{
Coordination mode engineering in stacked- nanosheet metal-organic frameworks to enhance catalytic reactivity and structural robustness
}

Chuanhui Huang 1,2,3,7, Juncai Dong (10 4,7, Weiming Sun ${ }^{5,7}$, Zhenjie Xue ${ }^{1,3}$, Jun Ma', Lirong Zheng ${ }^{4}$, Cong Liu ${ }^{1,3}$, Xiao Li ${ }^{1}$, Kang Zhou ${ }^{6}$, Xuezhi Qiao (1) ${ }^{1,3}$, Qian Song ${ }^{1,3}$, Wende Ma², Lan Zhang ${ }^{2}$, Zhenyu Lin (D) ${ }^{2}$ \& Tie Wang (D) ${ }^{1,3}$

Optimising the supported modes of atom or ion dispersal onto substrates, to synchronously integrate high reactivity and robust stability in catalytic conversion, is an important yet challenging area of research. Here, theoretical calculations first show that three-coordinated copper $(\mathrm{Cu})$ sites have higher activity than four-, two- and one-coordinated sites. A siteselective etching method is then introduced to prepare a stacked-nanosheet metal-organic framework (MOF, CASFZU-1)-based catalyst with precisely controlled coordination number sites on its surface. The turnover frequency value of CASFZU-1 with three-coordinated $\mathrm{Cu}$ sites, for cycloaddition reaction of $\mathrm{CO}_{2}$ with epoxides, greatly exceed those of other catalysts reported to date. Five successive catalytic cycles reveal the superior stability of CASFZU-1 in the stacked-nanosheet structure. This study could form a basis for the rational design and construction of highly efficient and robust catalysts in the field of single-atom or ion catalysis.

\footnotetext{
${ }^{1}$ Beijing National Laboratory for Molecular Sciences, Key Laboratory of Analytical Chemistry for Living Biosystems and Colloid, Interface and Chemical Thermodynamics, Institute of Chemistry, Chinese Academy of Sciences, \#2 Zhongguancun, North First Street, Beijing 100190, China. ${ }^{2}$ Ministry of Education Key Laboratory for Analytical Science of Food Safety and Biology, Fuzhou University, Fuzhou, Fujian 350116, China. ${ }^{3}$ University of Chinese Academy of Sciences, Beijing 100049, China. ${ }^{4}$ Beijing Synchrotron Radiation Facility, Institute of High Energy Physics, Chinese Academy of Sciences, 19 B Yuquan Rd, Beijing 100049, China. ${ }^{5}$ The Department of Basic Chemistry, The School of Pharmacy, Fujian Medical University, Fuzhou, Fujian 350108, China. ${ }^{6}$ State Key Laboratory of Structure Chemistry, Fujian Institute of Research on the Structure of Matter, Chinese Academy of Sciences, Fuzhou, Fujian 350002, China. ${ }^{7}$ These authors contributed equally: Chuanhui Huang, Juncai Dong, Weiming Sun. Correspondence and requests for materials should be addressed to Z.L. (email: zylin@fzu.edu.cn) or to T.W. (email: wangtie@iccas.ac.cn)
} 
$\mathrm{M}$ onodispersed single atoms and ions on solid substrates, as unsaturated coordinated metal sites, have recently emerged as an exciting class of catalysts that combine the merits of both homogeneous and heterogeneous catalysts ${ }^{1-3}$. However, most studies to date used specific materials as supporting substrates to anchor the active metal site, which prohibited the further optimisation of catalytic activity ${ }^{4,5}$. Metal-organic frameworks (MOFs), which are formed by coordination bonds between metal nodes and organic linkers, have tailored structures and great functional tunability 6,7 . Therefore, MOFs may be good candidates for exploration of the relationship between the catalytic performance and anchored mode of metal sites. Some studies have reported specific functionalities arising from open metal sites or certain defects, e.g., under-coordinated metal sites, such as improved adsorption affinity or catalytic activity $^{8-12}$. However, major challenges for further improved design and construction of future generations of unsaturated coordinated metal sites are the production of a series of metal sites with systematically tunable coordination modes, and the establishment of a definitive correlation between the catalytic properties and coordination state. Furthermore, the robustness of a framework is often vulnerable to changes in the metal-ligand interactions. Frameworks with under-coordinated metal sites collapse easily upon thermal or catalytic treatment ${ }^{13-15}$. These limitations represent a major challenge in establishing the exact structure-to-property correlation in coordinatively unsaturated metal atoms for catalysis, which is essential for the rational design and synthesis of coordinatively unsaturated metal sites with tailored activities under the premise of ensuring stability of the structure.

In this study, we take inspiration from the hexagonal-shaped cells of a honeycomb, which provide relatively high out-of-plane compression and shear properties ${ }^{16,17}$ and develop a strategy for etching stacked-nanosheet MOFs (CASFZU-1) with threecoordinated copper $(\mathrm{Cu})$ by selectively etching the classical HKUST-1 along the (111) facets. Measurements of the catalytic efficiency of stacked-nanosheet MOFs show a higher turnover frequency (TOF) for $\mathrm{CO}_{2}$ fixation with large epoxides (i.e., 2octyloxirane and 1,2-epoxydodecane) compared to most other catalysts reported to date. In addition, they have a long catalytic lifetime of four recovery cycles and bulk production yields several kilograms at a time. Therefore, such MOFs are potentially suitable as practical catalysts and are promising candidate materials for industrial applications.

\section{Results}

Design and theoretical prediction. While the nanosheets intersect at lines converging at angles of $60^{\circ}$ and $120^{\circ}$, these triangular or hexagonal structures prevent the material from collapsing by evenly distributing stress loads ${ }^{18}$. Therefore, in comparison to freestanding MOF nanosheets, we obtained an MOF that is more stable under the thermodynamic and kinetic conditions that arise during the catalytic reaction (Fig. 1a). In addition to enhancing the activities of $\mathrm{Cu}$ sites, the three-coordinated $\mathrm{Cu}$ sites on the surface of the stacked MOF nanosheets also increased the affinity between the active sites and the reactant. As shown in Fig. 1b and Supplementary Figure 1, showing the electrostatic surface potential (ESP) diagrams obtained from density functional theory (DFT)-based calculations, the activities of the three-coordinated $\mathrm{Cu}(0.056 \mathrm{au})$ with more $\sigma$-holes were higher than those of pristine four-coordinated $\mathrm{Cu}(0.040 \mathrm{au})$ and of both twocoordinated and one-coordinated $\mathrm{Cu}(0.028$ and $0.046 \mathrm{au}$, respectively $)^{19}$. We analysed the frontier molecular orbitals $(\mathrm{MOs})^{20}$, according to which the three-coordinated $\mathrm{Cu}$ sites have the smallest gap between their highest occupied molecular orbital
(HOMO) and lowest unoccupied molecular orbital (LUMO) of $1.38 \mathrm{eV}$, whereas the four-, two- and one-coordinated sites have HOMO-LUMO gaps of $1.43 \mathrm{eV}, 4.51 \mathrm{eV}$, and $3.02 \mathrm{eV}$, respectively (as shown in Fig. 1c). This suggests that three-coordinated $\mathrm{Cu}$ is superior for applications involving covalent bonding with a soft base ${ }^{21}$.

Synthesis and characterisation. We used a two-step stackednanosheet MOF (CASFZU-1) preparation method (Fig. 2a). First, pristine HKUST-1 film was synthesised on a nylon 66 membrane as described previously with some modifications ${ }^{22}$ (Supplementary Figures 1-5), and second the as-prepared HKUST-1 film was etched controllably by water vapour and stored in a container at $25 \%$ relative humidity $(\mathrm{RH})$ at room temperature for a few days (Supplementary Figures 5 and 6), accompanied by mesopores ranging from a few to several hundreds of nanometres in size.

The formation of the CASFZU-1 crystal followed a surface energy-driven mechanism. The interaction energy between metal ions and carboxyl $\mathrm{O}$ atoms was similar to that between metal ions and water $\mathrm{O}$ atoms. The coordinated ligands in the MOF crystal were readily replaced by water molecules ${ }^{23}$. Calculations indicated that the surface energies of the (111), (110) and (100) planes in the HKUST-1 face-centred-cubic crystal followed the order $\boldsymbol{\gamma}_{(\mathbf{1 1 1})}<\boldsymbol{y}_{(\mathbf{1 0 0})}<\boldsymbol{y}_{(\mathbf{1 1 0})}$ (Supplementary Figures $7-9$ and Supplementary Note 1). A series of etched products were obtained by altering the etching conditions and by adjusting the $\mathrm{RH}$ and solvent polarity (SP) (Fig. 2b-e, Supplementary Figures 10-14, Supplementary Table 1). HKUST-1 is stable in the absence of liquid water or at low $\mathrm{RH}$ (i.e., 15\% RH) and the $\mathrm{Cu}$ sites were all four-coordinated by ligands (Fig. 2b). At $25 \%$ $\mathrm{RH}$, when the SP ranged from 4.30 to 7.25 (Supplementary Figures 11 and 14$)^{24}$, the MOF film composed of MOF nanosheets $9.25 \pm 0.28 \mathrm{~nm}$ thick (ca. 2-unit cell thickness) (Supplementary Figure 15) retained its structural integrity (Fig. 2c, Supplementary Figures 16 and 17). We exposed the threecoordinated $\mathrm{Cu}$ sites by strictly limiting etching along the (111) facets of the crystal structure (Supplementary Figure 18). The angles between two lines along the intersection between nanosheets that intersect at three (111) facets measure $60^{\circ}$, and the dihedral angle formed by the facets of each of the adjacent sheets is $70.529^{\circ}$ (Supplementary Figure 18). We identified the perfect (111) crystalline facets by measuring the corresponding selected area electron diffraction (SAED) pattern (Fig. $2 \mathrm{~g}$ ) and analysing high-resolution transmission electron microscopy (HRTEM) images. The lattice fringes at interplanar distances of $0.23 \mathrm{~nm}$ corresponded to the $d_{880}$ planes of the MOF crystal (Fig. 2h, i, Supplementary Figure 19). As SP was increased to 10.2, the (100) facets of the octahedral crystals became unstable, and the (111) and (100) facets were both etched to form anisotropically shaped pores from randomly etched MOFs (Fig. 2d), predominated by three-, two- and one-coordinated $\mathrm{Cu}$ sites. Large surface relaxations may occur when any $\mathrm{Cu}$ atom is coordinated with one or two benzene-1,3,5-tricarboxylate (TMA) linkers, which would decrease the stability of the MOF network. Further, when the RH exceeded 50\%, all facets of the crystal were 1 destroyed (Fig. 2e), resulting in large cleavages and structural collapse (denoted as collapsed MOFs) (Supplementary Figure 20).

The replacement of organic ligands by water molecules was verified for pristine and etched MOF films using energydispersive X-ray spectroscopy (EDX) mapping and X-ray photoelectron spectroscopy (XPS). These techniques established that CASFZU-1 had $59.25 \%, 46.7 \%$, and $94.9 \%$ more $\mathrm{Cu}$ on the surface than pristine HKUST-1, random-etching and collapsed MOFs, respectively. (Supplementary Figures 21 and 22 and Supplementary Table 2). The shift in the peak corresponding to 

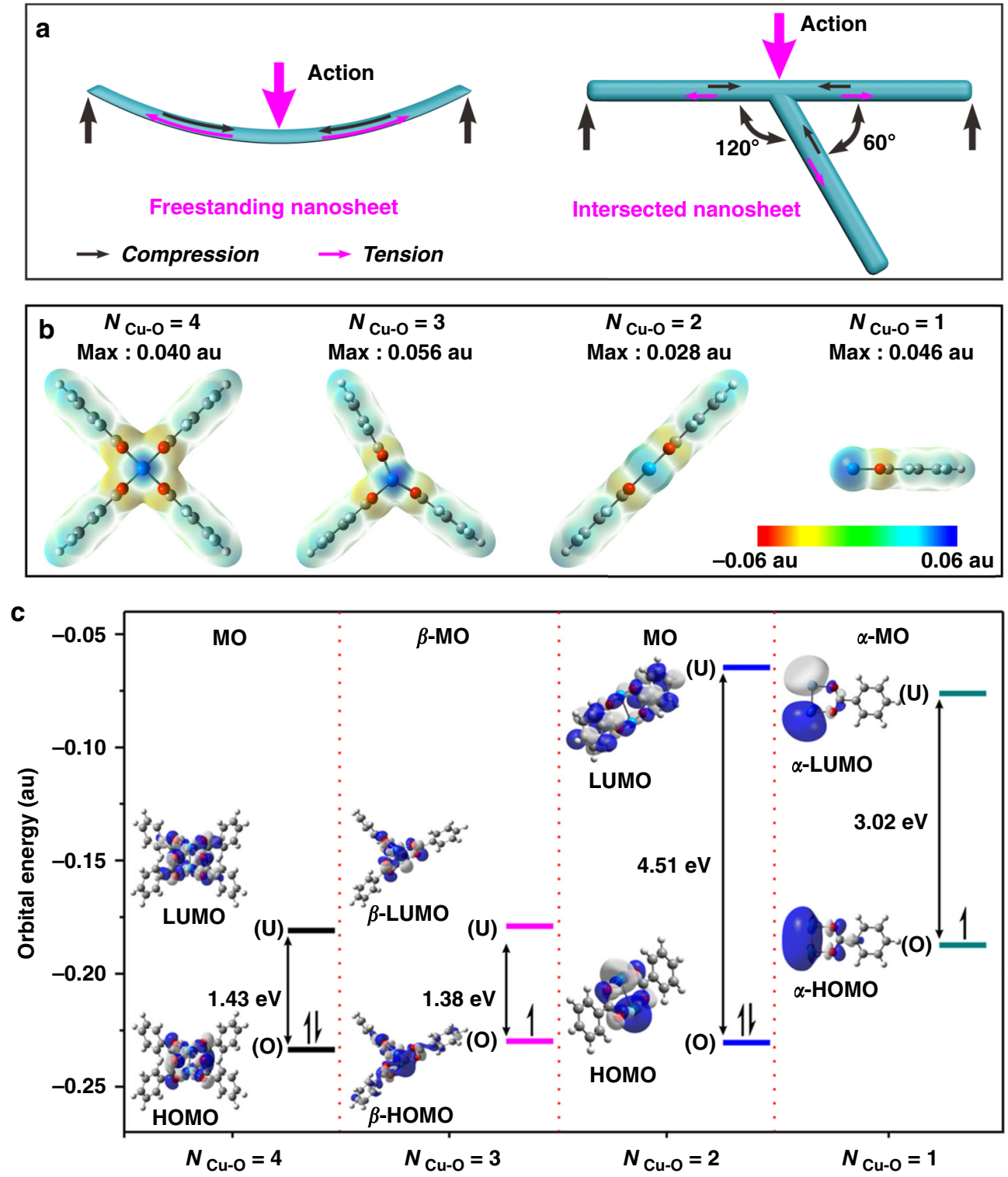

Fig. 1 Structural stability and physical properties of paddlewheel $\mathrm{Cu}_{2}$ clusters. a A schematic overview of displacements for the freestanding metal-organic framework (MOF) nanosheet and intersected-nanosheet under the same acting force. $\mathbf{b}$ Electrostatic surface potential (ESP) maps of paddlewheel $\mathrm{Cu}_{2}$ clusters. $\mathrm{N}_{\mathrm{Cu}-\mathrm{O}}$ represents the paddlewheel $\mathrm{Cu}_{2}$ clusters with different coordination numbers $(\mathrm{CNs})$ of $\mathrm{Cu}-\mathrm{O}(4,3,2,1)$ (isovalue $=0.001$ e per bohr ${ }^{3}$ ) c The simulated frontier orbital energy levels and molecular orbital $(\mathrm{MO})$ diagrams (isovalue $=0.02 \mathrm{au}$ ) of paddlewheel $\mathrm{Cu}_{2}$ clusters with different $\mathrm{CNs}$ of $\mathrm{Cu}-\mathrm{O}(4,3,2,1)$. Only the $\beta$-MO and $\alpha$-MO with smaller energy gaps are shown for the open-shell three- and one-coordinated copper (Cu) catalysts. Colour scheme for chemical representation: cyan, $\mathrm{Cu}$; red, O; grey, $\mathrm{C}$; white, $\mathrm{H}$

$\mathrm{Cu}$ (II) species undergoing transformation to higher energy (from 940.3 to $940.8 \mathrm{eV}$ ) indicated that the $\mathrm{Cu}$ ions remained divalent but become more active in CASFZU-1 (Supplementary Figure 22). These $\mathrm{Cu}$ species in CASFZU-1 were visibly and rapidly reduced to the $\mathrm{Cu}$ crystal by electron beam irradiation during TEM (Supplementary Figure 23). On in situ Fourier transform-infrared (FT-IR) spectra (Supplementary Figure 24), the gradual increases in intensity of the bands at 1704 and $1277 \mathrm{~cm}^{-1}$ corresponding to the $\mathrm{C}=\mathrm{O}$ and $\mathrm{C}-\mathrm{OH}$ combination bands of a carboxylic acid, respectively, indicated transformation of the $\mathrm{Cu}$-TMA carboxylate groups to their protonated acid analogues ${ }^{25}$. Compared to the pristine HKUST-1 $\left(1550 \mathrm{~m}^{2} \mathrm{~g}^{-1}\right)$, the BET surface area for CASFZU-1 decreased to $1043 \mathrm{~m}^{2} \mathrm{~g}^{-1}$, suggesting that part of the inherent porous structure was blocked after some ligands fell off the MOF. In contrast to site-selective etching, faster degradation kinetics resulting in porosity of the MOFs was $c a$.
$60 \%$, and completely lost for random-etching MOFs $\left(638 \mathrm{~m}^{2} \mathrm{~g}^{-1}\right)$ and collapsed MOFs $\left(7.0 \mathrm{~m}^{2} \mathrm{~g}^{-1}\right)$, respectively (Supplementary Figure 25).

Atomic structure analysis of copper site. To confirm the etching transformation process from HKUST-1 to CASFZU-1 proposed in Fig. 2a, the evolution of the local atomic arrangements and chemical state of $\mathrm{Cu}$ species were investigated by X-ray absorption spectroscopy (XAS), including extended X-ray absorption fine structure (EXAFS) and X-ray absorption near-edge structure (XANES). The etching and dehydration effects were first identified by EXAFS analysis. Figure 3a shows the EXAFS Fourier transform (FT) magnitude of CASFZU-1 before and after dehydration (denoted as CASFZU-1-dehy), along with the pristine HKUST-1. Their EXAFS spectra exhibited similar envelopes 

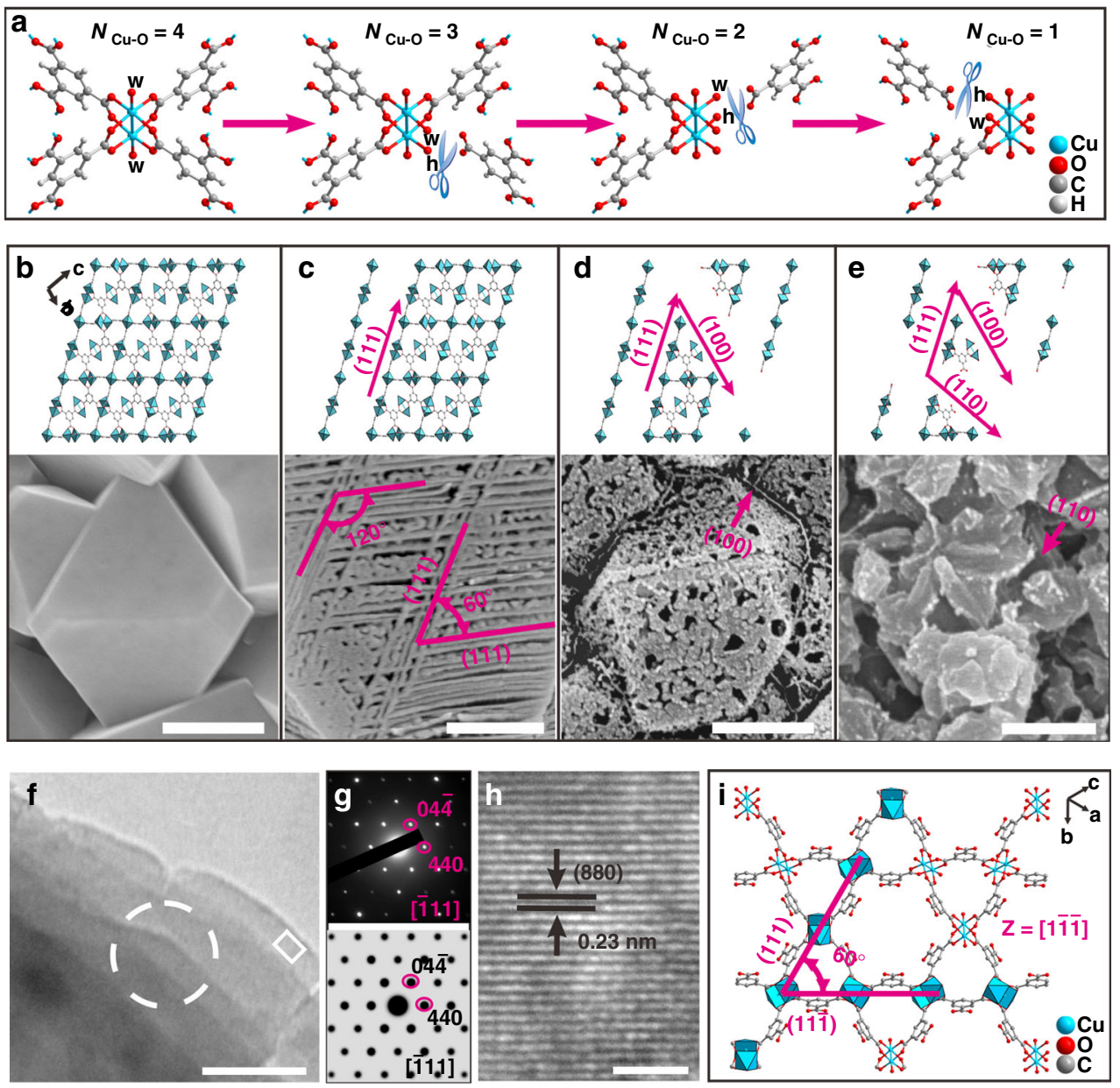

Fig. 2 Synthetic strategy and structural characterisation. a Schematic overview of the etching transformation of four-coordinated Cu atoms to three-, twoand one-coordinated $\mathrm{Cu}$ atoms with organic ligands ( $\mathrm{w}$ represents oxygen atom from the water, and $\mathrm{h}$ represents oxygen atom from the hydroxide anion, $\mathrm{OH}^{-}$). b-e Model structures and real morphologies of the four different MOF crystal states after etching. b Pristine HKUST-1 MOFs, c stacked-nanosheet MOFs, $\mathbf{d}$ random-etching MOFs, e collapsed MOFs. $\mathbf{f}$ Transmission electron microscopy (TEM) top-view image of a five-layered CASFZU-1 thin nanosheet. $\mathbf{g}$ Selected area electron diffraction (SAED) pattern (taken from the white-circled region in $\mathbf{f}$ ) at the top shows diffraction within a few-layered nanosheet. A simulated SAED pattern of the HKUST-1 crystal down the [111] axis is also shown. $\mathbf{h}$ High-resolution TEM (HR-TEM) image of the white-framed region at the edge of the nanosheet shown in $\mathbf{f}$. i The crystal structure of HKUST-1 along the [111] direction. Scale bars represent $500 \mathrm{~nm}$ for $\mathbf{b}, \mathbf{d}$, and $\mathbf{e}, 200 \mathrm{~nm}$ for $\mathbf{d}$, $100 \mathrm{~nm}$ for $\mathbf{f}$ and $2 \mathrm{~nm}$ for $\mathbf{h}$. Colour scheme for chemical representation: cyan, Cu; red, O; grey, C; white, H

featuring a main peak at $1.50 \AA$ arising from $\mathrm{Cu}-\mathrm{O}$ bonding as well as several minor peaks located at $2.05,2.41$, and $2.83 \AA$ dominated by higher-shell $\mathrm{Cu}-\mathrm{C}, \mathrm{Cu}-\mathrm{Cu}$ and $\mathrm{Cu}-\mathrm{O}$ scattering, respectively (Supplementary Figure 26). When etching HKUST-1 to CASFZU-1, the $\mathrm{Cu}-\mathrm{O}$ and $\mathrm{Cu}-\mathrm{Cu}$ peaks showed subtle changes, whereas the $\mathrm{Cu}-\mathrm{C}$ peak exhibited an obvious decrease in intensity (Fig. 3a), which could be attributed to the partial removal of carboxylate ligand. In contrast, further dehydration treatment of CASFZU-1 resulted in remarkable decreases in intensity for the main $\mathrm{Cu}-\mathrm{O}$ peak, as well as the higher-shell $\mathrm{Cu}-\mathrm{Cu}$ and $\mathrm{Cu}-\mathrm{O}$ peaks, with a slight change for the $\mathrm{Cu}-\mathrm{C}$ peak (Fig. 3a). The underlying structural modifications were then extracted by quantitative EXAFS curve fitting analysis (see Methods). Our EXAFS analysis was first validated by the distortion of HKUST-1 upon dehydration (Supplementary Figures 27-31 and Supplementary Table 3); while all the scattering path lengths concerning the $\left[\mathrm{Cu}_{2} \mathrm{C}_{4} \mathrm{O}_{8}\right]$ framework cage showed obvious shrinking, the $\mathrm{Cu}-\mathrm{Ow}$ bond from water molecules showed a slight decrease in the coordination number $(\mathrm{CN})$ and a considerable increase in the Debye-Waller factor, in good agreement with previous results ${ }^{26}$. However, it is interesting that the etching of HKUST-1 to CASFZU-1 produced visible elongation for the higher coordination shells (i.e., $\mathrm{Cu}-\mathrm{C} 1$, $\mathrm{Cu}-\mathrm{Cu} 1$ and $\mathrm{Cu}-\mathrm{O} 2$ ) (Supplementary Figure 32 and Supplementary Table 3), suggesting expansion for the $\left[\mathrm{Cu}_{2} \mathrm{C}_{4} \mathrm{O}_{8}\right]$ framework cage. Moreover, the decreased $\mathrm{CNs}$ for the ligand-related paths confirmed etching of the carboxylate ligand on the surface of nanosheet CASFZU-1. The following dehydration treatment of CASFZU-1 caused contraction for all scattering path lengths (Fig. 3b, c and Supplementary Table 3), suggesting further shrinkage of the $\left[\mathrm{Cu}_{2} \mathrm{C}_{4} \mathrm{O}_{8}\right]$ framework cage, consistent with the distortion behaviour of HKUST-1 upon dehydration.

To better identify the defective $\mathrm{Cu}$ site structures, we then used XANES spectroscopy, which is more sensitive to the 3D arrangement of atoms around the photoabsorber. Figure 3d shows XANES profiles for HKUST-1, CASFZU-1 and CASFZU1-dehy, which are characterised by a pre-edge peak at 8978 due to $1 \mathrm{~s} \rightarrow 3 \mathrm{~d}$ transition, a shoulder peak at $8986 \mathrm{eV}$ ascribed to $1 \mathrm{~s} \rightarrow$ $4 \mathrm{p}$ dipolar shakedown transition, a white-line peak at $8,998 \mathrm{eV}$ and a resonance peak at $9042 \mathrm{eV}$. In contrast to the high degree of resemblance of CASFZU-1 to HKUST-1, CASFZU-1-dehy showed an apparent intensity increase for the pre-edge and shoulder peaks, as well as a considerable intensity decrease for the while-line peak, indicating thorough removal of water 

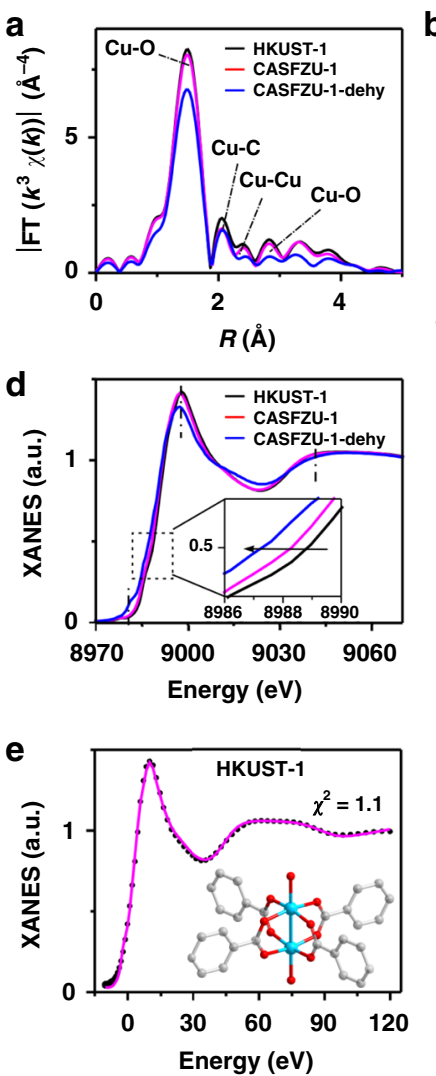
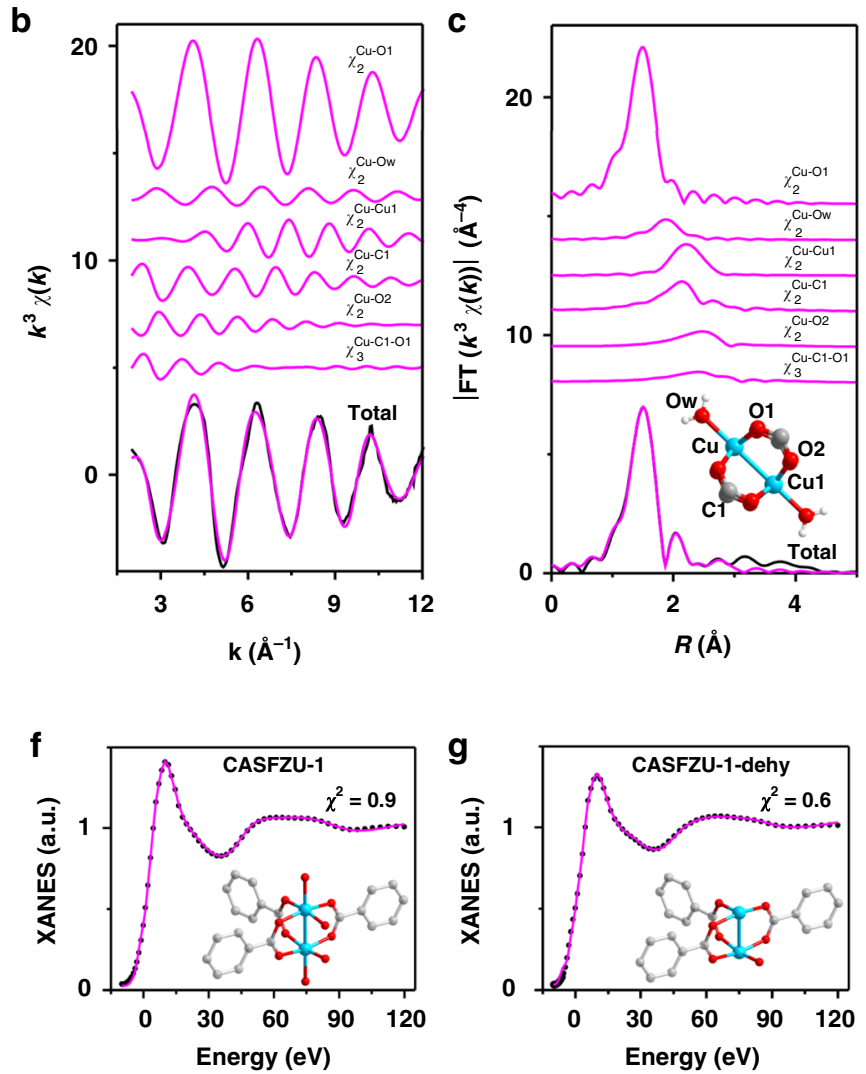

Fig. 3 Structural characterisation by EXAFS and XANES spectroscopy. a Fourier transformed magnitudes of the experimental K-edge EXAFS signals for HKUST-1 and CASFZU-1 samples before and after dehydration (denoted as CASFZU-1-dehy). The Fourier transforms are not corrected for phase shift. The origin assignment for the EXAFS peaks is given in Supplementary Figure 26. b, c Cu K-edge EXAFS analysis of CASFZU-1 after dehydration in $k$ and $R$ spaces, respectively. Curves from top to bottom are the single backscattering signal $\chi_{2}$ and double scattering signal $\chi_{3}$ included in the fit, and the total signal (red line) superimposed on the experimental signal (black line). The inset shows the structure of the hydrated $\left[\mathrm{Cu}_{2} \mathrm{C}_{4} \mathrm{O}_{8}\right]\left(\mathrm{H}_{2} \mathrm{O}\right)_{2}$ moiety used for simulation of the EXAFS signals. $\mathbf{d}$ The experimental Cu K-edge XANES spectra. e-g Comparison between the experimental XANES spectra (black dotted lines) and the best-fit theoretical spectra with the depicted structural models (solid red lines). e The hydrated $\left[\mathrm{Cu}_{2} \mathrm{C}_{4} \mathrm{O}_{8}\right]\left(\mathrm{H}_{2} \mathrm{O}\right)_{2} \mathrm{cage} \mathbf{f} \mathrm{The}_{\mathrm{defective}}$ three-coordinated $\left[\mathrm{Cu}_{2} \mathrm{C}_{3} \mathrm{O}_{6}\right]\left(\mathrm{H}_{2} \mathrm{O}\right)_{3} \mathrm{OH}$ cage. $\mathbf{g}$ The dehydrated three-coordinated $\left[\mathrm{Cu}_{2} \mathrm{C}_{3} \mathrm{O}_{6}\right] \mathrm{OH}$ paddlewheel model, where one of the two coordinatively unsaturated $\mathrm{Cu}$ atoms is directly bound by one hydroxide anion, $\mathrm{OH}^{-}$. Colour scheme for chemical representation: cyan, $\mathrm{Cu}$; red, $\mathrm{O}$; grey, $\mathrm{C}$ and white, $\mathrm{H}$

molecules $^{26}$, consistent with the marked colour changes in the samples (Supplementary Figure 33). Meanwhile, the progressive shift of the edge position toward the lower energy direction, along with etching and dehydration (see inset in Fig. 3d), indicated a gradually reduced oxidation state for the $\mathrm{Cu}$ species. The XANES spectra were then quantitatively analysed with the MXAN procedure to statistically discriminate the various plausible coordination models for $\mathrm{Cu}$ species (Supplementary Figure 34) based on fitting quality ${ }^{27-29}$ (i.e., the residue function $R_{\mathrm{sq}}$ ) (see Methods). The experimental XANES spectra for all the samples could be well reproduced by the hydrated $\left[\mathrm{Cu}_{2} \mathrm{C}_{4} \mathrm{O}_{8}\right]\left(\mathrm{H}_{2} \mathrm{O}\right)_{2}$ cage model (Fig. 3e, Supplementary Figures 35-37 and Supplementary Table 4), which not only indicated their dominance in the MOF framework but also validated our analysis. Upon dehydration, the dehydrated $\left[\mathrm{Cu}_{2} \mathrm{C}_{4} \mathrm{O}_{8}\right]_{2}$ cage model showed better agreement with the experimental spectrum of CASFZU-1-dehy $\left(R_{\mathrm{sq}}=0.6\right)$ than that of HKUST-1-dehy $\left(R_{\mathrm{sq}}=2.0\right)$ (Fig. $3 \mathrm{~g}$ and Supplementary Figure 35), consistent with more thorough removal of water molecules in the former. Importantly, we found that excellent agreement between the experimental and theoretical spectra for both CASFZU-1 and CASFZU-1-dehy could be obtained by the defective three-coordinated $\left[\mathrm{Cu}_{2} \mathrm{C}_{3} \mathrm{O}_{6}\right]\left(\mathrm{H}_{2} \mathrm{O}\right)_{3} \mathrm{OH}$ paddlewheel model (Fig. 3f, g and Supplementary Figures 36-37), indicating their presence on the exposed surfaces of CASFZU-1 nanosheets.
Furthermore, the experimental spectrum for CASFZU-1-dehy could be satisfactorily reproduced by the dehydrated threecoordinated $\left[\mathrm{Cu}_{2} \mathrm{C}_{3} \mathrm{O}_{6}\right] \mathrm{OH}$ paddlewheel model where one of the two coordinatively unsaturated $\mathrm{Cu}$ atoms was directly bound by one hydroxide anion $\left(\mathrm{OH}^{-}\right)$, suggesting that the threecoordinated structure can readily lose partial coordinated water molecules (Fig. 3g). Finally, it was noted that the bond metrics derived based on the hydrated $\left[\mathrm{Cu}_{2} \mathrm{C}_{4} \mathrm{O}_{8}\right]\left(\mathrm{H}_{2} \mathrm{O}\right)_{2}$ cage model clearly exhibited expansion for the $\mathrm{Cu}$ paddlewheel when etching HKUST-1 to CASFZU-1 and shrinkage by the successive dehydration of CASFZU-1, in good agreement with the structural variations determined by EXAFS analysis and DFT prediction (Supplementary Figures 38 and 39 and Supplementary Table 4). Therefore, our comprehensive structural analyses not only provided solid XAS spectroscopic fingerprints for the defective three-coordinated $\left[\mathrm{Cu}_{2} \mathrm{C}_{3} \mathrm{O}_{6}\right]\left(\mathrm{H}_{2} \mathrm{O}\right)_{4}$ paddlewheel model on the exposed surfaces of CASFZU-1 nanosheets, but also unambiguously revealed distortion during the etching transformation process from HKUST-1 to CASFZU-1.

Catalysed $\mathbf{C O}_{2}$ cycloaddition. We prepared quantities of CASFZU-1 on the order of kilograms using our method, which is reliable and simple to perform (Fig. 4a). We significantly improved 

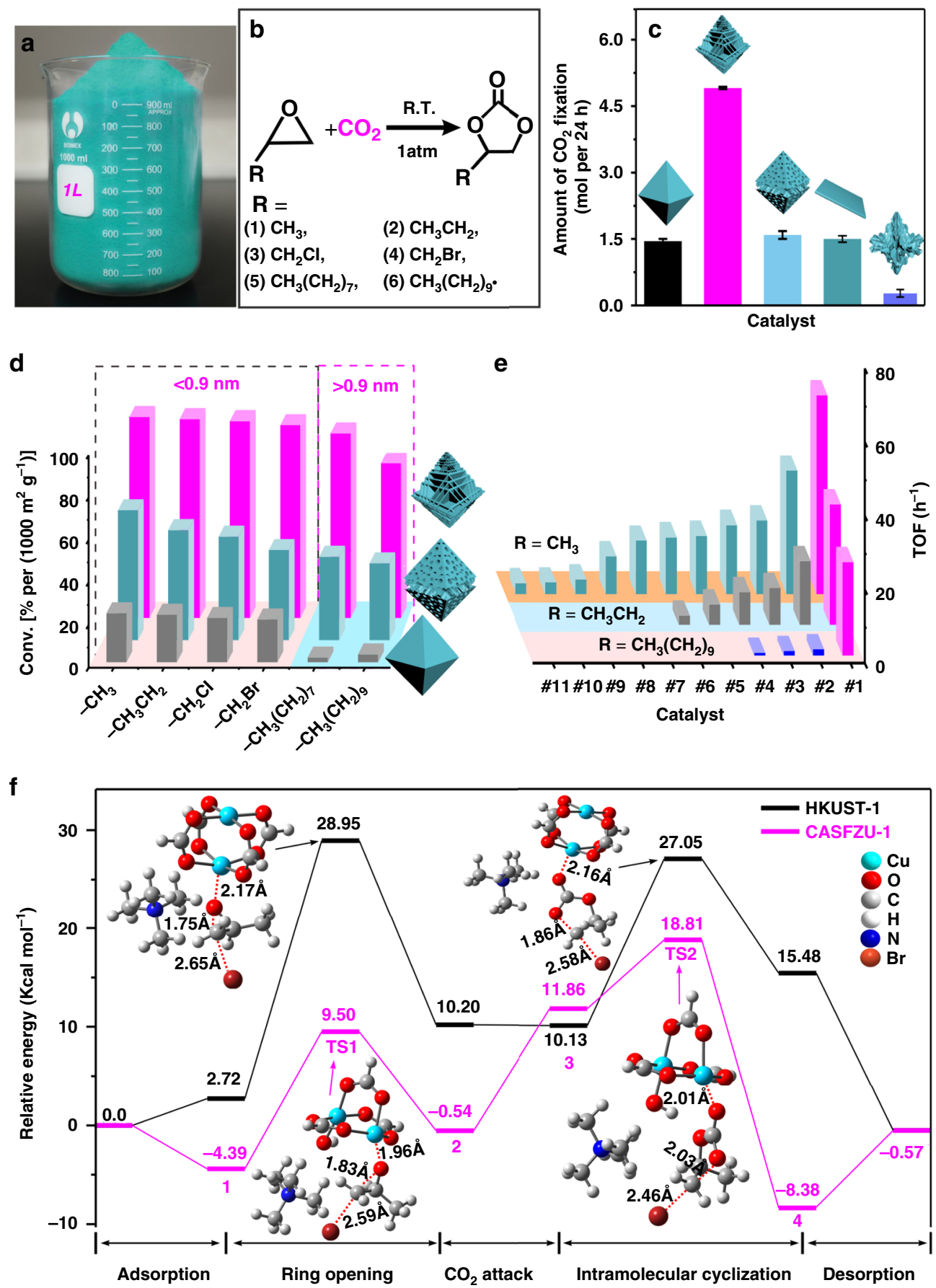

Fig. 4 Catalytic activity and density functional theory (DFT) calculations. a Photographs of the ca.1.0 kg of CASFZU-1 prepared in the laboratory. b Scheme for cycloaddition of $\mathrm{CO}_{2}$ with epoxides to produce cyclic carbonates catalysed by CASFZU-1. c The amount of $\mathrm{CO}_{2}$ fixation with 2-methyloxirane by chemical conversion reactions catalysed by $1 \mathrm{~g}$ of different MOFs in $24 \mathrm{~h}$. From left to right, the columns represent MOF crystals of pristine HKUST-1, CASFZU-1 and random-etching MOFs, HKUST-1 nanosheet and collapsed MOF forms. Error bars represent the standard deviation of three replicate samples. d Conversion for cycloaddition of $\mathrm{CO}_{2}$ with the six epoxides catalysed by HKUST-1 (grey), random-etching MOFs (light blue) and CASFZU-1 (red) after normalising BET. Columns from left to right represent 2-methyloxirane; 2-ethyloxirane; 2-(chloromethyl)oxirane; 2-(bromomethyl)oxirane; 2octyloxirane; and 1, 2-epoxydodecane. e Turnover frequency (TOF) comparison of CASFZU-1 with the other catalysts in representative publications on catalysis of the cycloaddition reaction of $\mathrm{CO}_{2}$ with 2-methyloxirane, 2-ethyloxirane and 1,2-epoxydodecane (see Supplementary Tables 7-9 for details). The rightmost red columns represent CASFZU-1. $\mathbf{f}$ The computed reaction energy profiles of the $\mathrm{CO}_{2}$ fixation reaction on HKUST-1 and CASFZU-1. TS, transition state. The pathways are divided into five steps: (i) adsorption of epoxy; (ii) epoxy ring opening step; (iii) $\mathrm{CO}_{2}$ electrophilic attack step; (iv) intramolecular cyclisation step; (v) product desorption (see Supplementary Figures 49, 51 and 52 for more details and references). Colour scheme for chemical representation: cyan, $\mathrm{Cu}$; red, O; grey, C; tangerine, Br; blue, $\mathrm{N}$; white, $\mathrm{H}$ 
the rate of cyclic carbonate production with strong Lewis acid $\mathrm{Cu}$ sites in CASFZU-1 (Supplementary Figure 40) and high affinity for $\mathrm{CO}_{2}$ (Fig. 4b, Supplementary Figures 41 and Supplementary Note 2 and Supplementary Table 5). CASFZU-1 exhibited the best catalytic reaction performance (Fig. 4c and Supplementary Figures 42-44) of the five different MOFs examined. In carbon fixation with 2methyloxirane, CASFZU-1 converted a comparable amount of $\mathrm{CO}_{2}$ per gram to that accumulated by $210 \mathrm{~m}^{2}$ of undisturbed tropical rainforest $^{30}$ (Supplementary Note 3 and Supplementary Figure 45). Notably, the experiments showed that the co-catalyst tetrabutylammonium bromide played a vital role in the ring-opening step for cyclic carbonate synthesis, and no significant catalytic activity was observed in the absence of tetrabutylammonium bromide. After normalising the BET, the cycloaddition yields of small molecules catalysed by CASFZU-1 were about four and two times higher than those of HKUST-1 and random-etching MOFs, respectively (Fig. $4 \mathrm{~d}$ and Supplementary Figure 25). The advantages of stacked-nanosheet MOFs are greater for large-sized molecules. CASFZU-1 has large mesopores $(4.0 \mathrm{~nm})$, resulting in conversion efficiencies of $87.3 \% \pm 1.2 \%$ and $72.9 \% \pm 3.0 \%$ for 2 -octyloxirane and 1,2-epoxydodecane, respectively (Fig. 4d, Supplementary Figure 46 and Supplementary Table 6), whereas these were $2.2 \% \pm$ $0.5 \%$ and $3.7 \% \pm 1.3 \%$ for HKUST-1 (with the largest entrance pore of $0.9 \mathrm{~nm})^{31}$; these conversion efficiencies were only $39.2 \% \pm 1.9 \%$ and $36.1 \% \pm 2.4 \%$, respectively, in random-etching MOFs (mesopore size, $3.6 \mathrm{~nm}$ ). As the random-etching MOFs have similar mesopore size to CASFZU-1, these marked differences in catalytic efficiency between them may have been because the threecoordinated $\mathrm{Cu}$ sites have the highest activity among the four coordination states. The catalytic cycloaddition reaction of $\mathrm{CO}_{2}$ with 2-methyloxirane and 2-ethyloxirane had TOF of $54.0 \mathrm{~h}^{-1}$ and $32.7 \mathrm{~h}^{-1}$ in CASFZU-1, respectively, and these catalytic efficiencies were more than twofold higher than the most efficient $\mathrm{Cu}$-based MOFs previously reported (Fig. 4e, Supplementary Tables 7 and 8). Furthermore, CASFZU-1 exceeded the maximum TOF for large substrate $\left(1,2\right.$-epoxydodecane, $\left.\quad \mathrm{TOF}=25.34 \mathrm{~h}^{-1}\right)$ by 20 -fold, because the large mesopores promote mass-transformation (Fig. $4 \mathrm{e}$ and Supplementary Table 9).

The high catalytic efficiency of CASFZU-1 was attributable to three aspects. First, the stabilisation of the structure by three TMA linkers may provide a lower steric hindrance effect, thereby enhancing the transformation of the reactants and accelerate product diffusion. The three-coordinated $\mathrm{Cu}$ sites with more $\sigma$-holes exhibit higher activity and higher binding affinities for epoxide molecules because of the smaller band gap compared with four-, two- and one-coordinated $\mathrm{Cu}$ sites. Second, threecoordinated $\mathrm{Cu}$ sites with high activity accelerate electron transfer and bonding. The relevant partial density of states (PDOS) of HKUST-1 has a very low tail at the conduction band minimum, whereas CASFZU-1 has an obviously left-shifted peak. The unsaturated state of the $\mathrm{Cu}$ increased the state density of CASFZU-1 at the edge of the conduction band (Supplementary Figure 47). These results indicated that the $3 d e_{\mathrm{g}}$ states of the coordinatively unsaturated $\mathrm{Cu}$ atoms were filled with more electrons in CASFZU-1 than in bulk HKUST-1, unambiguously indicating that under-coordinated $\mathrm{Cu}$ atoms are more reactive ${ }^{11}$. Third, a reliable Lewis acid-based catalytic mechanism can explain the enhanced catalytic performance of CASFZU-1 from the free energy viewpoint. Taking propylene oxide as an example, the DFT was applied to calculate the relative free energy for the intermediates, transition states and products in the cycloaddition promoted by catalyst and co-catalyst, respectively (Fig. $4 \mathrm{f}$ and Supplementary Figures 48-52). Without the co-catalyst, the energy barrier for the rate-limiting step was as high as $62.52 \mathrm{kcal}$ $\mathrm{mol}^{-1}$ and almost no reaction occurred (Supplementary Figure 50). After adding co-catalyst to the catalytic system, cycloaddition was carried out in multiple reaction steps. The transition state and corresponding energy barrier of the two main steps, i.e., ring opening and intramolecular cyclisation, are shown in Fig. 4f. The epoxide ring-opening step (TS1) with an energy barrier of $26.23 \mathrm{kcal} \mathrm{mol}^{-1}$ became the rate-limiting step with the highest energy barrier for cycloaddition promoted by HKUST-1 (Fig. 4f). The energy barrier of this step for CASFZU-1 with three-coordinated $\mathrm{Cu}$ sites was only $13.89 \mathrm{kcal} \mathrm{mol}^{-1}$, which was smaller than that for HKUST-1, suggesting a key role of the threecoordinated $\mathrm{Cu}$ sites in this reaction. Furthermore, the overall energy barrier for CASFZU-1 $\left(23.20 \mathrm{kcal} \mathrm{mol}^{-1}\right)$ was markedly reduced compared to that for HKUST-1 $\left(28.95 \mathrm{kcal} \mathrm{mol}^{-1}\right)$, thus providing CASFZU-1 with enormous catalytic acceleration.

Mechanical stability and reconstruction. In addition, because the stacked-sheet structure enables distribution of the stress or strain developed during the chemical reaction, the CASFZU-1 catalyst showed better catalytic stability than HKUST-1 nanosheets and random-etching MOFs. The morphology and framework of CASFZU-1 were well retained after five successive catalytic cycles, indicating the long-term stability of the catalyst (Fig. 5a-c and Supplementary Figures 53 and 54). However, as significant breakage and agglomeration of fragments occurred, the catalytic activities of random-etching MOFs and monodispersed HKUST1 nanosheets were only $44.4 \%$ and $23.0 \%$, respectively (Fig. 5d-I, $\mathrm{k}$, and Supplementary Figures 55 and 56). The greatly enhanced structural stability of CASFZU-1 was attributed to the regular triangular shape formed by the intersection of the nanosheets at a perfect $60^{\circ}$ angle. The stress generated by adsorption of molecules during a catalytic process can be mitigated by this unique mechanical structure. When one side of the triangle suffers external stress, the other two sides offer counteracting stresses guaranteeing minimal deformation of the nanosheets under external stress, consistent with our simulated results. Under the same external stress, the displacements of CASFZU-1, random-etching MOFs and HKUST-1 nanosheets were 76, 119 and 246, respectively (Fig. 5c, f, i).

Unlike other MOF nanosheets, we can alter the catalytic performance of these MOFs by varying their structures between those of HKUST-1 and CASFZU-1. We filled in and smoothed most of the visible interlayer of the CASFZU-1 by treatment with a solution containing a certain concentration of organic ligands at room temperature. This increased the intensity of the powder Xray diffraction (XRD) peaks attributed to HKUST-1 (Supplementary Figures 57 and 58). In comparison with HKUST-1 (yields of $30.0 \% \pm 1.6 \%$ for $\mathrm{H} 1,28.0 \% \pm 2.7 \%$ for $\mathrm{H} 2,25.0 \% \pm$ $4.0 \%$ for $\mathrm{H} 3$ and $21.0 \% \pm 2.5 \%$ for $\mathrm{H} 4$ ), the regenerated CASFZU1 (yields of $98.0 \% \pm 1.3 \%$ for $\mathrm{C} 1,93.0 \% \pm 2.3 \%$ for $\mathrm{C} 2,85.0 \% \pm$ $2.8 \%$ for $\mathrm{C} 3$ and $70.0 \% \pm 3.8 \%$ for $\mathrm{C} 4$ ) clearly showed better performance with regard to converting $\mathrm{CO}_{2}$ into cyclic carbonates (Fig. 5j and Supplementary Figures 59 and 60). A thin CASFZU-1 film attached to a flexible polymer membrane provided good reusability and convenient transferability, which enabled the framework to maintain its shape and catalytic activity even after five successive catalytic cycles (Fig. 5k and Supplementary Figure 61). The performance and stability were far superior to those of the random-etching MOFs and HKUST-1 nanosheets.

\section{Discussion}

In summary, controllable and precise etching of the organic ligands on the surface of MOF catalysts enabled the construction of a stacked-nanosheet superstructure, the planes of which intersected at a perfect $60^{\circ}$ angle. The highly active threecoordinated $\mathrm{Cu}$ sites were effective for important cycloaddition reaction of $\mathrm{CO}_{2}$, inducing activity markedly exceeding the 

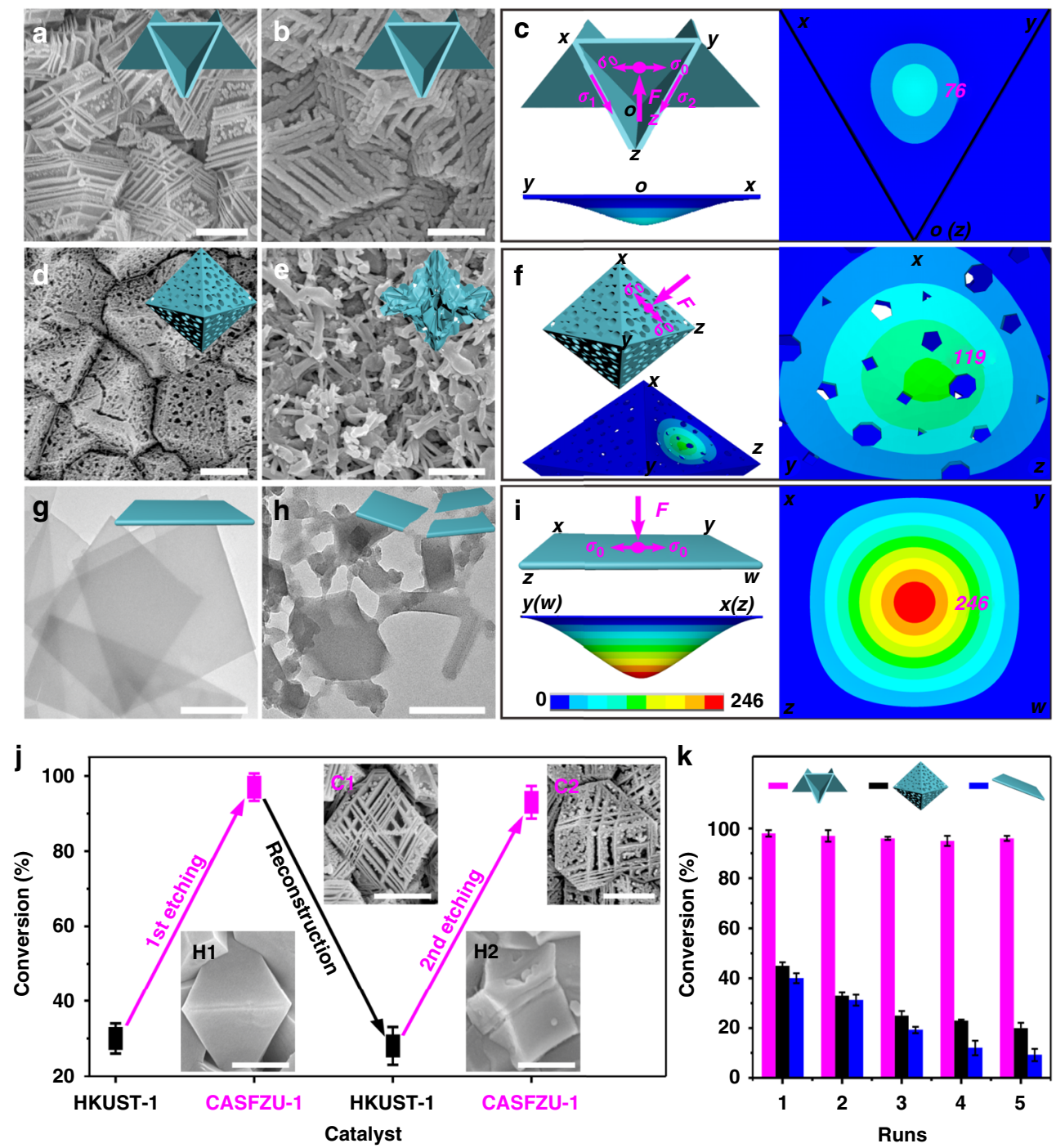

Fig. 5 Mechanical stability and reconstruction of CASFZU-1. a, b Scanning electron microscopy (SEM) images of CASFZU-1 before and after five runs of catalysed reaction. $\mathbf{c}$ The model of CASFZU-1 and its simulated cloud pictures of the displacement distribution profiles under an external stress, F. d, e SEM images of random-etching MOFs before and after five runs of catalysed reaction. $\mathbf{f}$ The model of random-etching MOFs and its simulated cloud picture of the displacement distribution profiles under an external stress, F. $\mathbf{g}$, $\mathbf{h}$ Transmission electron microscopy (TEM) images of a monodispersed HKUST-1 nanosheet before and after five runs of catalysed reaction. $\mathbf{i}$ The model of the HKUST-1 nanosheets and its simulated cloud picture of the displacement distribution profiles under external stress, $F$. $\mathbf{j}$ Recoverability of CASFZU- 1 and its catalytic activity after reconstruction. The transformation of CASFZU- 1 into HKUST-1 via reaction with $5 \mathrm{mM} \mathrm{H}_{3} \mathrm{BTC}$ and all of the CASFZU-1 (C1, C2) had higher activities than HKUST-1 (H1, H2). k Recyclability characterisation of CASFZU-1 (red), random-etching MOFs (black) and HKUST-1 nanosheets (blue) for five runs of catalysed $\mathrm{CO}_{2}$ for cycloaddition reaction with 2-ethyloxirane. Scale bars represent $500 \mathrm{~nm}$ for $\mathbf{a}, \mathbf{b}, \mathbf{d}, \mathbf{e}, \mathbf{g}, \mathbf{h}$ and $\mathbf{j}$. Error bars represent the standard deviation of three replicate samples

maximum values of previous reported catalysts, especially under industrially favoured conditions of non-energy consumption. The CASFZU-1 heterogeneous catalyst could maintain undiminished activity in marked contrast to the nanosheet catalyst that typically suffers from fragmentation and aggregation to form large unreactive species that prevent continuity of the reaction. Our systematic studies revealed that three-coordinated $\mathrm{Cu}$ sites played a significant role in achieving high efficiency, and the special geometric superstructure determined the robust characteristics of the CASFZU-1 catalyst. In addition, the recoverability of the catalyst demonstrated a strategy for the design and development of heterogeneous catalysts that are highly efficient toward chemical transformations and have long life cycles. It is important to further explore how this synthesis route and advanced structure can be used to tune the reactivity of diverse heterogeneous systems.

\section{Methods}

Preparation of bulk HKUST-1 and CASFZU-1. Equal volumes of $4 \mathrm{mM}$ copper nitrate solution and $1.4 \mathrm{mM}$ aminoethanol solution were rapidly mixed and aged at $60^{\circ} \mathrm{C}$ for $1 \mathrm{~h}$. Filtering $60 \mathrm{~mL}$ of the mixture solution through a nylon 66 microporous membrane left a thin light blue film on the membrane. The obtained film was reacted with $15 \mathrm{~mL}$ of $5 \mathrm{mM}$ trimesic acid ethanol/water $(1: 1 \mathrm{v} / \mathrm{v})$ solution at room temperature. A pure HKUST-1 thin film was formed typically after $1 \mathrm{~h}$. To obtain the CASFZU-1 thin film, the membrane holding the pure HKUST-1 thin film was dried at $60^{\circ} \mathrm{C}$ for $10 \mathrm{~min}$ to remove residual solvent and then stored at $\mathrm{RH}$ $25 \%$ for 1 month.

Reconstruction of CASFZU-1. A used CASFZU-1 thin film was reacted with $10 \mathrm{~mL}$ of $5 \mathrm{mM} \mathrm{H}_{3} \mathrm{BTC}$ ethanol/water $(1: 1 \mathrm{v} / \mathrm{v})$ solution at room temperature. A pure HKUST-1 thin film was formed typically after $30 \mathrm{~min}$. The membrane holding the pure HKUST- 1 thin film was then dried at $60^{\circ} \mathrm{C}$ for $10 \mathrm{~min}$ to remove residual solvent and stored at RH $25 \%$ for 1 month to produce CASFZU-1.

Two-step preparation of HKUST-1 nanosheets. Preparation of $\mathrm{Cu}_{2} \mathrm{O}$ nanocubes $^{32}$ : Typically, cupric chloride $\left(\mathrm{CuCl}_{2} ; 0.10 \mathrm{mmol}\right)$ and polyvinylpyrrolidone 
(PVP; $0.10 \mathrm{~g}$ ) were dissolved in $40.0 \mathrm{~mL}$ of deionised water, followed by dropwise addition (1 drop per s) of $2.5 \mathrm{~mL}$ of $0.2 \mathrm{M} \mathrm{NaOH}$ solution; the mixture was stirred magnetically for $5 \mathrm{~min}$. Then, $2.5 \mathrm{~mL}$ of $0.10 \mathrm{M}$ ascorbic acid solution was added dropwise ( 1 drop per $3 \mathrm{~s}$ ) and the solution was further stirred for $5 \mathrm{~min}$. Finally, the cubic $\mathrm{Cu}_{2} \mathrm{O}$ nanoparticles were suspended in $10 \mathrm{~mL}$ of ethanol $(\mathrm{Cu}$ concentration: ca. $10 \mathrm{mM}$ ) for future investigation.

Preparation of HKUST-1 nanosheets ${ }^{33}$ : Typically, $0.4 \mathrm{~g}$ of PVP was dissolved in $60 \mathrm{~mL}$ of water and then $0.2 \mathrm{~g}$ of TMA dissolved in $4 \mathrm{~mL}$ of ethanol was added. The white mixture was stirred for $5 \mathrm{~min}$ before the addition of $10 \mathrm{~mL}$ of $\mathrm{Cu}_{2} \mathrm{O}$ ethanolic suspension. The mixture became transparent within $1 \mathrm{~min}$. After stirring for $2 \mathrm{~h}$, the solution became a pale blue turbid suspension, which indicated the formation of HKUST-1 nanosheets. The mixture was stirred for $16 \mathrm{~h}$ at room temperature. The solid product was then rinsed twice with ethanol/water and vacuum-dried at room temperature before further use.

\section{Carbon fixation catalysed by HKUST-1 and CASFZU-1. The catalyst was} vacuum-dried at $150{ }^{\circ} \mathrm{C}$ overnight before use. The catalytic reaction was typically conducted in a three-necked flask containing epoxide $(25 \mathrm{mmol})$ and purged with a flow of $\mathrm{CO}_{2}$ at a pressure of $1 \mathrm{~atm}$ in a solvent-free environment at room temperature. The added catalyst was $0.125 \mathrm{~mol} \%$ per $\mathrm{Cu}$ paddlewheel unit of MOF (5.5 mg for HKUST-1, random-etching MOFs, collapsed MOFs and CASFZU-1) with a co-catalyst of tetra- $n$-tetrabutylammonium bromide (TBAB, $0.65 \mathrm{~g}, 10 \mathrm{~mol}$ $\%)$. The reaction was allowed to proceed for $36 \mathrm{~h}(22 \mathrm{~h}$ for 2 -methyloxirane). The products were analysed by gas chromatography (GC; model 6820; Agilent Technologies, Santa Clara, CA, USA) equipped with a flame-ionisation detector and further identified by comparing GC retention times and mass spectra with those of authentic samples. The recovered catalyst was collected by centrifugation, then vacuum-dried at $120^{\circ} \mathrm{C}$ overnight.

Characterisation. The products were characterised by XRD (model D/MAX2500; Rigaku, Tokyo, Japan) with $\mathrm{Cu}-\mathrm{Ka}$ radiation at a scan rate of $3^{\circ} \mathrm{min}^{-1}$. The in situ FT-IR spectra were measured using a Nicolet iS 50 instrument (Thermo Fisher Scientific, Waltham, MA, USA) from 550 to $4000 \mathrm{~cm}^{-1}$ with resolution of $8 \mathrm{~cm}^{-1}$, using 64 scans by the $\mathrm{KBr}$ tableting method. Before measurements, samples were degassed in vacuo $\left(10^{-5} \mathrm{Torr}\right)$ at $250^{\circ} \mathrm{C}$ for $1 \mathrm{~h}$. The surface area and pore diameter were determined with a physisorption analyser (model ASAP $2020 \mathrm{M}$; Micromeritics, Norcross, GA, USA) at $-196^{\circ} \mathrm{C}$. Before measurements, samples were degassed in vacuo at $180^{\circ} \mathrm{C}$ for at least $8 \mathrm{~h}$. The Brunner-Emmet-Teller (BET) method was used to calculate the specific surface areas (SBET) using adsorption data at $P / P_{0}$ of $0.05-0.30$. The pore size distributions (PSDs) were derived from the adsorption branches of the isotherms using the Barrett-Joyner-Halenda $(\mathrm{BJH})$ model. The total pore volume $\left(V_{\mathrm{t}}\right)$ was estimated from the adsorbed amount at $P / P_{0}$ of 0.995 . We conducted gas sorption analyses using a Micromeritics ASAP 2020 with extra-high purity gases at $298 \mathrm{~K}$. We degassed the samples in vacuo at $180^{\circ} \mathrm{C}$ for at least $8 \mathrm{~h}$ prior to the measurements. Thermogravimetric analysis (TGA) was carried out using a Pyris 1 TGA (PerkinElmer, Waltham, MA, USA) with a nitrogen flow rate of $10 \mathrm{~mL} \mathrm{~min}^{-1}$. The morphologies were characterised by scanning electron microscopy (SEM; S-4800; Hitachi, Tokyo, Japan) equipped for EDX analysis. The TEM images were obtained using Hitachi H-800 and JEOL JEM-2010 (JEOL, Tokyo, Japan) instruments at an acceleration voltage of $200 \mathrm{kV}$.

X-ray absorption data collection, analysis and modelling. Cu K-edge X-ray absorption spectra were acquired under ambient conditions in transition mode at beamline 1W1B of Beijing Synchrotron Radiation Facility (BSRF), using a Si (111) double-crystal monochromator. The storage ring of BSRF was operated at $2.5 \mathrm{GeV}$ with a maximum current of $250 \mathrm{~mA}$ in decay mode. While the energy was calibrated using $\mathrm{Cu}$ foil, both the incident and transmitted X-ray intensities were monitored using standard ion chambers. The XAFS raw data were backgroundsubtracted, normalised and Fourier-transformed by standard procedures with the ATHENA program ${ }^{34}$ Least-squares curve fitting analysis of the EXAFS $\chi(k)$ data was carried out using the ARTEMIS program ${ }^{34,35}$, based on the standard EXAFS equation consisting of single and multiple-scattering expansions. The scattering amplitudes and phase shifts for all paths, as well as the photoelectron mean free path, were theoretically calculated by ab initio code FEFF9. $0^{36}$. The Hedin-Lundqvist self-energy and simple final-state rule core hole were used, via which an account of charge transfers between the absorber $\mathrm{Cu}$ and surrounding atoms and accurate determination of Fermi level enabled us to perform the fit with a single energy shift, $\Delta E_{0}$. The passive electron reduction factor $S_{0}{ }^{2}$ was determined in the fit of $\mathrm{CuO}$ standard and fixed in the rest of the EXAFS models. All the EXAFS data for HKUST-1 and CASFZU-1 samples before and after dehydration were modelled with the hydrated $\left[\mathrm{Cu}_{2} \mathrm{C}_{4} \mathrm{O}_{8}\right]\left(\mathrm{H}_{2} \mathrm{O}\right)_{2}$ cage (see Supplementary Figure 34a) to allow optimisation of the occupancy of absorbed water molecules during the fitting procedure, consistent with the strategy reported in ref. ${ }^{26}$. Specifically, six significant paths were used to interpret the FT-transformed EXAFS signal in the 1.0-3.0 $\AA$ range; they included the $\mathrm{Cu}-\mathrm{O} 1, \mathrm{Cu}-\mathrm{C}, \mathrm{Cu}-\mathrm{Cu}$ and $\mathrm{Cu}-\mathrm{O} 2$ single-scattering (SS) paths, as well as the $\mathrm{Cu}-\mathrm{O} 1-\mathrm{C} 1$ double-scattering path from the carboxylate ligand and the $\mathrm{Cu}-\mathrm{Ow}$ SS path from water molecules, as shown schematically in Supplementary Figure 29. All fits were performed in the $R$ space with $k$-weight of 3 . The EXAFS $R$-factor $\left(R_{\mathrm{f}}\right)$ that measures the percentage misfit of the theory to the data was used to evaluate the goodness of fit. The best-fit results are shown in Fig. 3b, c and Supplementary Figures 30-32, with the fitting parameter values listed in Supplementary Table 3.

Quantitative XANES fitting was carried out with the MXAN code in the framework of the full multiple-scattering scheme using Muffin-tin approximation for the potential 27,28 . The energy-dependent exchange-correlation potential was calculated in the real Hedin-Lundqvist scheme. Inelastic processes were taken into account by convolution with a broadening Lorentzian function having an energydependent width of the form $\left.\Gamma(E)=\Gamma_{c}+\Gamma_{m f p} E\right)$, in which the constant part $\Gamma_{c}$ takes care of both the core-hole lifetime and the experimental resolution, while the energy-dependent term represents intrinsic and extrinsic inelastic processes. The minimisation of the XANES spectra for HKUST-1 and CASFZU-1 samples before and after dehydration was carried out starting from all plausible coordination structures for $\mathrm{Cu}$ cations, as shown schematically in Supplementary Figure 34. The fitting quality was evaluated using the square residue function $\left(R_{\mathrm{sq}}\right)$, where a statistical weight of 1 and a constant experimental error of $1.2 \%$ were used, with the best-fit results shown in Fig. 3e-g and Supplementary Figures 34-37; the structural parameters are shown in Supplementary Table 4

Theoretical models and DFT calculations. All of the DFT calculations in this work were carried out using the B3PW91 density function ${ }^{37}$ in the GAUSSIAN 09 software package ${ }^{38}$. The Los Alamos double-zeta-type LANL2DZ and effective core potential (ECP) basis sets were used for the $\mathrm{Cu}$ and $\mathrm{Br}$ atoms, while the $6-311+G(d, p)$ split valence basis set was used for the other atoms for geometric optimisation and frequency calculations. Intrinsic reaction coordinate (IRC) calculations were performed at the B3PW91/6-31 + G(d)/LANL2DZ level to confirm that a given transition state connects a particular pair of consecutive minima. Based on the optimised structures, the zero-point-corrected Gibbs free energy at $298 \mathrm{~K}$ was calculated at the same computational level to obtain the potential energy surface profiles of the cycloaddition reaction. The HOMO, LUMO and electronic static potential (ESP) were generated by the GaussView program ${ }^{39}$, while the total density of states (TDOS) and PDOS were obtained by Multiwfn 3.3.7 software ${ }^{40}$.

Simulation of strain profiles. The cloud picture of the displacement distribution profiles after processing was simulated using ANSYS engineering software. The model used to simulate the cloud picture of the displacement distribution consisted of three plates made of two-dimensional HKUST-1 nanosheets of dimensions $1000 \times 1000 \times 10 \mathrm{~nm}^{3}$; the intersecting lines of the three plates converged at perfect $60^{\circ}$ angles and the facets of all adjacent plates formed a dihedral angle of $70.529^{\circ}$ We used a model of (random-etching MOFs) octahedral HKUST-1 of dimensions $1000 \mathrm{~nm} \times 1000 \mathrm{~nm}$ (bottom square) $\times 750 \mathrm{~nm}$ (height for the rectangular pyramid) to simulate the cloud picture of the displacement distribution. The material properties were as follows: density, $1.22 \times 10^{-6} \mathrm{ng} \mathrm{nm}^{-3}$; elastic modulus, $5 \mathrm{GPa}^{41}$, and Poisson's ratio, $0.3^{42}$. The octahedron and plates were constrained as follows. The displacements of the most external nodes of the constrained edges were zero in three directions. Simulated loads were applied to the plates as $20-\mathrm{nN}$ forces at the centres of $10 \times 10 \mathrm{~nm}^{2}$ regions ${ }^{15}$

\section{Data availability}

The data that support the findings of this study are available from the corresponding author upon request.

Received: 19 February 2019 Accepted: 1 May 2019

Published online: 25 June 2019

\section{References}

1. Lin, S. et al. Covalent organic frameworks comprising cobalt porphyrins for catalytic $\mathrm{CO}_{2}$ reduction in water. Science 349, 1208-1213 (2015).

2. Peng, Y. et al. A versatile MOF-based trap for heavy metal ion capture and dispersion. Nat. Commun. 9, 187 (2018).

3. Fei, H. et al. General synthesis and definitive structural identification of $\mathrm{MN}_{4} \mathrm{C}_{4}$ single-atom catalysts with tunable electrocatalytic activities. Nat. Catal. 1, 63-72 (2018).

4. Wang, A., Li, J. \& Zhang, T. Heterogeneous single-atom catalysis. Nat. Rev. Chem. 2, 65-81 (2018).

5. Chen, Y. et al. Single-atom catalysts: synthetic strategies and electrochemical applications. Joule 2, 1242-1264 (2018).

6. Liu, J. et al. Applications of metal-organic frameworks in heterogeneous supramolecular catalysis. Chem. Soc. Rev. 43, 6011-6061 (2014).

7. Lee, J. et al. Metal-organic framework materials as catalysts. Chem. Soc. Rev. 38, 1450-1459 (2009).

8. $\mathrm{Wu}, \mathrm{H}$. et al. Unusual and highly tunable missing-linker defects in zirconium metal-organic framework UiO-66 and their important effects on gas adsorption. J. Am. Chem. Soc. 135, 10525-10532 (2013). 
9. Bennett, T. D., Cheetham, A. K., Fuchs, A. H. \& Coudert, F.-X. Interplay between defects, disorder and flexibility in metal-organic frameworks. Nat. Chem. 9, 11-16 (2016).

10. Xiao, D. J. et al. Oxidation of ethane to ethanol by $\mathrm{N}_{2} \mathrm{O}$ in a metal-organic framework with coordinatively unsaturated iron(II) sites. Nat. Chem. 6, 590-595 (2014).

11. Zhao, S. et al. Ultrathin metal-organic framework nanosheets for electrocatalytic oxygen evolution. Nat. Energy 1, 16184 (2016).

12. Xiao, X. et al. A general approach to cobalt-based homobimetallic phosphide ultrathin nanosheets for highly efficient oxygen evolution in alkaline media. Energy Environ. Sci. 10, 893-899 (2017).

13. Tan, J. C. \& Cheetham, A. K. Mechanical properties of hybrid inorganicorganic framework materials: establishing fundamental structure-property relationships. Chem. Soc. Rev. 40, 1059-1080 (2011).

14. Tan, J. C., Bennett, T. D. \& Cheetham, A. K. Chemical structure, network topology, and porosity effects on the mechanical properties of Zeolitic Imidazolate Frameworks. Proc. Natl Acad. Sci. USA 107, 9938-9943 (2010).

15. Tan, J.-C., Saines, P. J., Bithell, E. G. \& Cheetham, A. K. Hybrid Nanosheets of an Inorganic-Organic Framework Material: Facile Synthesis, Structure, and Elastic Properties. ACS Nano 6, 615-621 (2012).

16. Lakes, R. Materials with structural hierarchy. Nature 361, 511-515 (1993).

17. Masuda, H. \& Fukuda, K. Ordered metal nanohole arrays made by a two-step replication of honeycomb structures of anodic alumina. Science $\mathbf{2 6 8}$, 1466-1468 (1995).

18. Asimow, L. \& Roth, B. The rigidity of graphs, II. J. Math. Anal. Appl. 68, 171-190 (1979).

19. Stenlid, J. H. \& Brinck, T. Extending the $\sigma$-hole concept to metals: an electrostatic interpretation of the effects of nanostructure in gold and platinum catalysis. J. Am. Chem. Soc. 139, 11012-11015 (2017).

20. Snyder, B. E. R. et al. The active site of low-temperature methane hydroxylation in iron-containing zeolites. Nature 536, 317-321 (2016).

21. Pearson, R. G. Recent advances in the concept of hard and soft acids and bases. J. Chem. Educ. 64, 561-567 (1987).

22. Mao, Y. et al. General incorporation of diverse components inside metal-organic framework thin films at room temperature. Nat. Commun. 5, 5532 (2014).

23. Greathouse, J. A. \& Allendorf, M. D. The interaction of water with MOF-5 simulated by molecular dynamics. J. Am. Chem. Soc. 128, 10678-10679 (2006).

24. Burtch, N. C., Jasuja, H. \& Walton, K. S. Water stability and adsorption in metal-organic frameworks. Chem. Rev. 114, 10575-10612 (2014).

25. Majano, G. et al. Solvent-mediated reconstruction of the metal-organic framework HKUST-1 $\left(\mathrm{Cu}_{3}(\mathrm{BTC})_{2}\right)$. Adv. Funct. Mater. 24, 3855-3865 (2014).

26. Prestipino, C. et al. Local structure of framework $\mathrm{Cu}$ (II) in HKUST-1 metallorganic framework: spectroscopic characterization upon activation and interaction with adsorbates. Chem. Mater. 18, 1337-1346 (2006).

27. Benfatto, M., Congiu-Castellano, A., Daniele, A. \& Della Longa, S. MXAN: a new software procedure to perform geometrical fitting of experimental XANES spectra. J. Synchrotron Rad. 8, 267-269 (2001).

28. Hayakawa, K., Hatada, K., Longa, S. D., D’Angelo, P. \& Benfatto, M. Progresses in the MXAN fitting procedure. AIP Conf. Proc. 882, 111-113 (2007)

29. Zitolo, A. et al. Identification of catalytic sites for oxygen reduction in ironand nitrogen-doped graphene materials. Nat. Mater. 14, 937-942 (2015).

30. Grace, J. et al. Carbon dioxide uptake by an undisturbed tropical rain forest in Southwest Amazonia, 1992 to 1993. Science 270, 778-780, (1995).

31. Wehring, M. et al. Self-diffusion studies in CuBTC by PFG NMR and MD simulations. J. Phys. Chem. C 114, 10527-10534 (2010).

32. Yec, C. C. \& Zeng, H. C. Synthetic architecture of multiple core-shell and yolk-shell structures of $\left(\mathrm{Cu}_{2} \mathrm{O} @\right)_{n} \mathrm{Cu}_{2} \mathrm{O}(n=1-4)$ with centricity and eccentricity. Chem. Mater. 24, 1917-1929 (2012).

33. Zhan, G. \& Zeng Hua, C. Synthesis and Functionalization of Oriented Metal-Organic Framework Nanosheets: Toward a Series of 2D Catalysts. Adv. Funct. Mater. 26, 3268-3281 (2016).

34. Ravel, B. \& Newville, M. ATHENA, ARTEMIS, HEPHAESTUS: data analysis for X-ray absorption spectroscopy using IFEFFIT. J. Synchrotron Rad. 12, 537-541 (2005).

35. Koningsberger, D. \& Prins, R. X-ray absorption: principles, applications, techniques of EXAFS, SEXAFS, and XANES. (eds Koningsberger, D. C. \& Prins, R.) Vol. 92 (Wiley, New York, 1988).
36. Rehr, J. J. \& Albers, R. C. Theoretical approaches to x-ray absorption fine structure. Rev. Mod. Phys. 72, 621-654 (2000)

37. Becke, A. D. Density-functional thermochemistry. III. The role of exact exchange. J. Chem. Phys. 98, 5648-5652 (1993).

38. Frisch, M. et al. J. Gaussian 09, Revision B. 01, Gaussian. Inc. (Wallingford, CT, 2010).

39. Dennington, R., Keith, T. \& Millam, J. GaussView, version 5. Semichem Inc., (Shawnee Mission, KS, 2009).

40. Lu, T. \& Chen, F. Multiwfn: a multifunctional wavefunction analyzer. J. Comput. Chem. 33, 580-592 (2012).

41. Wang, X. et al. Reversed thermo-switchable molecular sieving membranes composed of two-dimensional metal-organic nanosheets for gas separation. Nat. Commun. 8, 14460 (2017).

42. Venkatasubramanian, A. et al. MOF@MEMS: Design optimization for high sensitivity chemical detection. Sens. Actuat. B: Chem. 168, 256-262 (2012).

\section{Acknowledgements}

This work was financially supported by the National Natural Science Foundation of China (21635002, 21621062, 201874005, 21575027, 11605225, 21603032), and the National Key Research and Development Program of China Grant No. 2018YFA0208800. All the theoretical calculations were undertaken on the resources of the National Supercomputing Center in Shenzhen for providing computational resources.

\section{Author contributions}

T.W. and Z.L. proposed the research direction and guided the project. C.H. designed and performed the experiments. W.S., J.M., C.H. performed and analysed the theoretical calculations. J.D., Li.Z. analysed and interpreted the experimental data of XAS. K.Z. contributed to analysis of crystal structure and building the structural model. Z.X., C.L., X.L., X.Q., Q.S., W.M., La.Z. joined the discussion of data and gave useful suggestions. T.W., C.H. and J.D. analysed the experimental results and drafted the manuscript.

\section{Additional information}

Supplementary Information accompanies this paper at https://doi.org/10.1038/s41467019-10547-9.

Competing interests: The authors declare no competing interests.

Reprints and permission information is available online at http://npg.nature.com/ reprintsandpermissions/

Peer review information: Nature Communications thanks Huijun Zhao and the other, anonymous, reviewer(s) for their contribution to the peer review of this work.

Publisher's note: Springer Nature remains neutral with regard to jurisdictional claims in published maps and institutional affiliations.

Open Access This article is licensed under a Creative Commons Attribution 4.0 International License, which permits use, sharing, adaptation, distribution and reproduction in any medium or format, as long as you give appropriate credit to the original author(s) and the source, provide a link to the Creative Commons license, and indicate if changes were made. The images or other third party material in this article are included in the article's Creative Commons license, unless indicated otherwise in a credit line to the material. If material is not included in the article's Creative Commons license and your intended use is not permitted by statutory regulation or exceeds the permitted use, you will need to obtain permission directly from the copyright holder. To view a copy of this license, visit http://creativecommons.org/ licenses/by/4.0/.

(C) The Author(s) 2019 